\title{
The role of claw color in species recognition and mate choice in a fiddler crab
}

\author{
M. L Dyson ${ }^{1}$ (D) - D. M Perez ${ }^{2} \cdot$ T Curran $^{3} \cdot$ E. L McCullough ${ }^{2} \cdot$ P. R. Y Backwell ${ }^{2}$
}

Received: 25 November 2019 / Revised: 22 July 2020 / Accepted: 27 August 2020 / Published online: 4 September 2020

(C) The Author(s) 2020

\begin{abstract}
Many animal signals are brightly colored and convey information about species identity as well as information about individual conspecifics. Colorful bird and lizard signals have received much attention, and many studies have related specific spectral properties of these signals to variation in mating success and territory defense. Far less attention has been given to invertebrates even though there are spectacularly colorful species. The enlarged claw of the male banana fiddler crab Austruca mjoebergi, for example, is bright yellow and contrasts vividly against the mudflat substrate. It is used in waving displays to attract females and in male territory defense and combat. Claw color varies among males in the degree of "yellowness," ranging very pale yellow to orange. In this study, we examined female responses to claw color variation in two-choice tests using robotic crabs. We found that although females strongly discriminate against colors that fall outside the natural range of intensity, hue, and chroma, they show no consistent preferences for different claw colors within the natural range, and no single component of claw color (hue, chroma, or intensity) independently affected female choices. Using three-choice tests, we also showed that female preferences induce stabilizing selection on male claw color. We conclude that, although claw color is sufficient to facilitate species recognition, it is unlikely to be used in intraspecific mate choice to provide information about male quality.
\end{abstract}

\section{Significance statement}

Fiddler crabs are often brightly colored, are visually orientated animals, and have a highly complex social system. Despite this, there are few studies that have looked at the role of color in species recognition and mate choice in these animals. In this study, we use robotic crabs with painted claws to determine the role of claw color in species recognition and mate choice in the banana fiddler crab, Austruca mjoebergi. We found that color is important in conspecific mate recognition but the variation among males in claw "yellowness" is unlikely to be used by females in intraspecific mate choice decisions.

Keywords Fiddler crab $\cdot$ Austruca mjoebergi $\cdot$ Claw $\cdot$ Color $\cdot$ Mate choice $\cdot$ Species recognition

Communicated by T. Breithaupt

M. L Dyson

miranda.dyson@open.ac.uk

1 Department of Environment, Earth \& Ecosystems, The Open University, Walton Hall, Milton Keynes, UK

2 Research School of Biology, The Australian National University, ACT, Canberra 0200, Australia

3 School of Art and Design, The Australian National University, ACT, Canberra 0200, Australia

\section{Introduction}

Animal coloration plays an important role in both inter- and intraspecific communication. Many species from a wide variety of taxa have bright, complex color patterns that provide information about species identity (Losos 1985; Klomp et al. 2017), sex (Baldwin and Johnsen 2012), reproductive status (Cuadrado 2000), social status (Pryke et al. 2002), individual identity (Detto and Backwell 2009), and individual quality (see Svensson and Wong 2011 for review). Central to the use of color for effective communication is a strong link between perceivable signal variation and the information that is conveyed by the signal. Signals used in species recognition, for example, differ between species but show little withinspecies variation because the reliable identification of a 
conspecific would reduce the cost of mating with an incompatible mate and producing non-fertile offspring. In contrast, signals used to convey information about individual identity or quality can show high within-species variation (e.g., Ferreira and Ferguson 2002).

Color displays have long been implicated in contributing to behavioral and hence reproductive isolation between species. Some of the most well studied examples are plumage color in birds (Saetre et al. 1997), wing coloration in butterflies (Wiernasz and Kingsolver 1992; Jiggins et al. 2001), nuptial coloration in fish (Seehausen and van Alphen 1998; Williams and Mendelson 2011; Pauers et al. 2010), and dewlap color in lizards (Losos 1985; Klomp et al. 2017). Color signals are also widely implicated in intraspecific mate choice. In particular, it is widely accepted that females assess potential mates based on males' colorful ornaments because colorful displays are honest signals of male quality (see Svensson and Wong 2011 for review).

Decapod crustaceans are among the most brightly colored animal groups. They range in color from dull brown to vivid red or blue and show considerable variation in color patterning both between and within species (Caro 2018). However, despite this extraordinary diversity in coloration, almost nothing is known about its function and investigations into the perception of color and the use of color in species recognition and sexual selection is limited in this group (Caro 2018). There are few behavioral studies that have looked at the use of color in social interactions in crabs and only one that has examined the role of color in intraspecific mate choice. Baldwin and Johnson (2009) showed that blue crabs (Callinectes sapidus) are capable of color vision and that in two-choice tests, males respond preferentially to females with red claws over those with claws of various shades of orange (Baldwin and Johnsen 2012).

Fiddler crabs are well suited for studies on the adaptive significance of color ornaments. They show a high degree of color variation both between and within species, are visually orientated animals, and have highly complex social systems with an extensive behavioral repertoire (Detto and Backwell 2009; Zeil et al. 2006). Males are well known for their enlarged claw that they wave to attract females. The dynamic and spatial aspects of the wave itself are species-specific, as well as influencing mate choice (Callander et al. 2012; Mowles et al. 2017a), and convey species-specific information (Perez et al. 2012; Perez and Backwell 2017, 2019). Both the large claw and carapace are often brightly colored - with the carapace often changing color over a short time scale in response to environmental factors (Silbiger and Munguia 2008; Takashita 2019) while the claw maintains relatively constant color over much longer time periods (Wolfrath 1993; Takashita 2019).

Physiological studies investigating whether color represents a perceivable signal in fiddler crabs suggest that they have the capacity to see color. Hyatt's (1974) work on three species of fiddler crabs suggested the presence of at least two pigments with broad maximum sensitivity to wavelengths of between 400 (blue-violet) and $500 \mathrm{~nm}$ (red-orange). This was later supported by recordings from the optic nerve of Tubuca thayeri that suggested the presence of two visual pigments having peak spectral sensitives at $430 \mathrm{~nm}$ and $510-530 \mathrm{~nm}$ (Horch et al. 2002). A more recent study on four species of fiddler crabs (Jordão et al. 2007) showed one visual pigment present in retinal cells 1-7 with maximum sensitivity between 500 and $540 \mathrm{~nm}$ and the possibility of a second pigment in the eight retinal cells (R8). Finally, Rajkumar et al. (2010) found that in Leptuca pugilator, there are three opsin encoding genes: two that code for opsins sensitive to medium (433 $\mathrm{nm})$ and long $(497 \mathrm{~nm})$ wavelengths and one that is present only in the R8 photoreceptor cell that is sensitive to UV (360 $\mathrm{nm}$ ). This study therefore confirmed that it is highly likely that fiddler crabs have the basic molecular machinery for color perception - and may even be capable of trichromatic vision.

The fiddler crab, Astruca mjoebergi, is endemic to Australia. Males and females are characterized by mottled brown carapaces with traces of yellow or red. The enlarged male's claw is typically uniform yellow but shows a high degree of variation among males, ranging from pale yellow to orange (Fig. 1) with a mean reflectance maximum for the population at around $550 \mathrm{~nm}$. The claw also has a second, ultraviolet (UV) reflectance peak at approximately $325 \mathrm{~nm}$ (Detto and Backwell 2009).

Detto (2007) showed that in two-choice tests, female A. mjoebergi strongly prefer yellow painted claws over claws painted various shades of gray (different intensity or brightness) supporting physiological studies that suggest they are capable of discriminating between stimuli based on chromatic rather than achromatic (intensity) differences. Behavioral experiments on A. mjoebergi have also shown that yellow claw color is important in species recognition (Detto et al. 2006). In experiments with claws lacking UV, females strongly prefer males with yellow painted claws over those with claws painted to mimic that of a sympatric species $T$. signata (red and white). They also prefer claws shaped like a $T$. signata but painted yellow over conspecific shaped claws painted red and white to resemble $T$. signata. Both these results suggest color facilitates species recognition in this species, although it does not rule out a preference for a uniformly colored claw over a two-toned claw (i.e., choice based on color pattern). The fact that the claws lacked UV also suggests that although UV may play a role in species recognition, it is not essential, and crabs are able to rely on longer wavelengths alone to recognize conspecifics.

Although not required for conspecific mate recognition, there is some evidence in A. mjoebergi that UV is important in mate choice. When given a choice, females preferentially approach males with claws reflecting UV over males whose 


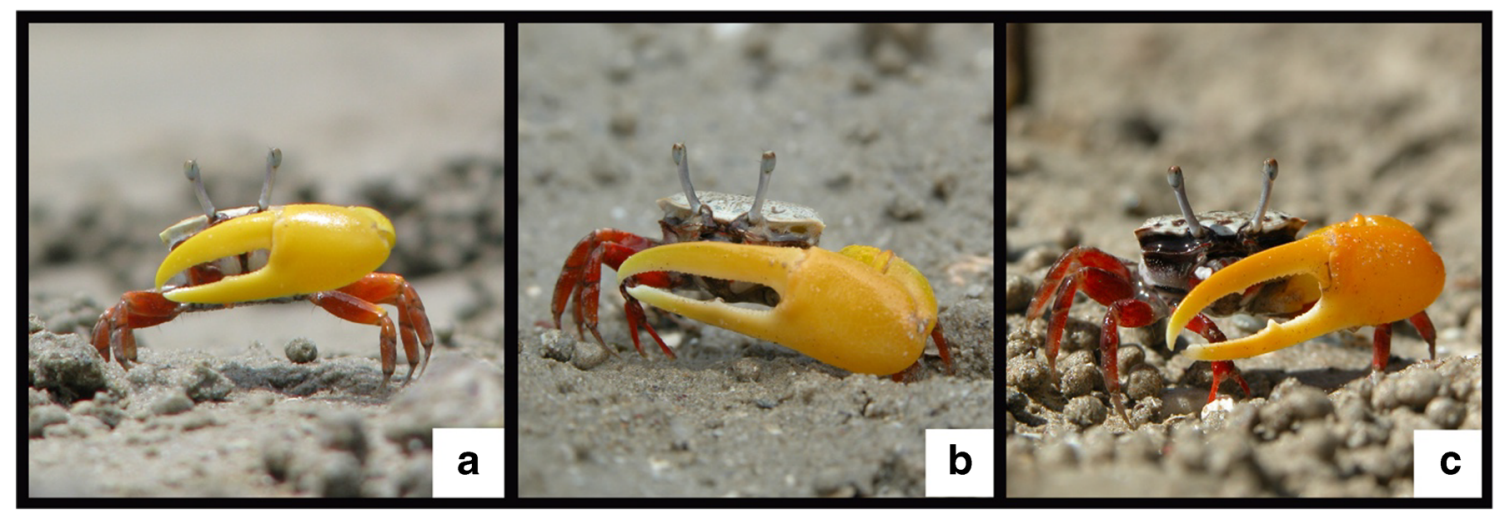

Fig. 1 Variation in the color of male claws from (A) light yellow (B) dark yellow to (C) orange

claws lack UV but are otherwise matched in color (Detto and Backwell 2009). The reason for this preference is unclear but may indicate a preference based on male quality that is correlated with UV reflectance or UV reflectance may simply increase male conspicuousness to females.

The aim of this study was twofold. The first aim was to determine the extent to which claw color, in the absence of UV reflectance, influences mate choice in A. mjoebergi. Although studies so far suggest a role for yellow claw color in species recognition, there have been no studies in this species that systematically investigates whether natural variation in male conspecific claw color from light yellow to orange and colors outside the species range affects species recognition and/or female mate choice. To do this, we conducted a series of two-choice experiments where we presented painted claws to females that ranged in color from white, light yellow, dark yellow, orange, and red. Since females are commonly confronted with more than two waving males under natural conditions, we also conducted a series of three-choice experiments to determine if an increase in the complexity of the signaling environment affected female mating decisions. Because we wanted to determine if longer wavelengths alone were sufficient to elicit preferential response from females, none of the claws in this study reflected UV.

The second aim of the study was to determine the extent to which different components of color (hue, chroma, and brightness) may affect mate choice. It is possible, for example, that hue (the dominant wavelength) influences female choice to a greater extent than chroma (saturation or purity of color) or intensity (brightness - the amount of light reflected). In some bird species, the different parameters of color have been shown to provide different kinds of information to females (e.g., Ferns and Hinsley 2008) and since natural claws may differ from one another in all these parameters, a lack of preference for one claw over another may result from an interaction between different color components. To test this possibility, we conducted a second set of two-choice experiments where claws presented to females differed markedly in one parameter (e.g., hue) while the other two parameters (in this case, chroma and intensity) were held as constant as possible.

\section{Methods}

\section{Study population}

We studied a population of A. mjoebergi in the mangroves of East Point Reserve, Darwin, Australia ( $12^{\circ} 24^{\prime} 032^{\prime \prime}$ S; $130^{\circ}$ $49^{\prime} 050^{\prime \prime}$ E) from September to December 2016, 2017, and 2018. They are small $(<2$-cm carapace width) crabs that live in dense, mixed-sex populations on intertidal mudflats across Northern Australia. At least five other species of fiddler crabs breed in sympatry with A. mjoebergi. Males wave their single enlarged claw to attract mate-searching females and in fighting other males. Both males and females own a territory that consists of a small area of mudflat surface $(10-20 \mathrm{~cm}$ in diameter) on which they feed. The males also use this area to court females. In the center of the territory is a burrow that is used as an escape from predators, a retreat from the high tide, a source of water, a heat sink, and a mating and incubation site (Detto et al. 2010). When ready to mate, a female leaves her territory and wanders through the population of waving males, visiting several males before selecting a mate. The pair mates underground, in the male's burrow. Once the female extrudes her eggs, the male leaves, sealing the female underground to incubate the eggs for 3 weeks. The larvae are released on a high spring tide so that they are rapidly washed out to sea where they form part of the plankton.

\section{Spectroscopy and color analysis}

We quantified the claw color of 40 males from the population as well as eight painted claw models used in the mate choice experiments (see below). We used a Jaz spectrometer (Ocean Optics) with a PX-2 light source (Ocean Optics). Three consecutive readings were taken from each of three different 
locations on the manus of each claw of males from the population and the painted claws used in the experiments. The fiber-optic reflectance probe was removed between scans. The probe was fitted with a tip (2.5-mm internal diameter) to standardize the distance between the probe and the claw surface. The tip was rested on the claw at a right angle to the surface. We used an integration time of $40 \mathrm{~ms}$ and a boxcar smoothing interval of $10 \mathrm{~ns}$. Measurements were made relative to a WS-2 white standard. We averaged the spectral reflectance of three readings for natural claws and painted claws over each $5 \mathrm{~nm}$ interval in the range of 300-700 nm.

We quantified coloration of the claws with respect to hue, chroma, and brightness using the segment classification method described by Endler (1990). Briefly, intensity was calculated as the total area under the spectral reflectance curve between 400 and $700 \mathrm{~nm}$, while chroma and hue were calculated by comparing values in the region $400-475 \mathrm{~nm}, 475$ $550 \mathrm{~nm}, 550-625 \mathrm{~nm}$, and $625-700 \mathrm{~nm}$ corresponding to the blue, green, yellow, and red regions of the spectrum. The relative brightness of each segment was calculated by summing the area under the curve and dividing by total brightness. Chroma was calculated using the formula:

$$
\sqrt{ }\left(L M^{2}+M S^{2}\right)
$$

where $L M$ is the proportion of light reflected at green (475$550 \mathrm{~nm}$ ) subtracted from the proportion of light reflected at red $(625-700 \mathrm{~nm})$ wavelengths and $M S$ is the proportion of light reflected at blue $(400-475 \mathrm{~nm})$ subtracted from the proportion of light reflected at yellow (550-625 nm) wavelengths. Hue (in degrees) was calculated using the formula (Smith 2014):

$$
H=\operatorname{arcSin}(M S / C) \text { modulus } 2 \pi
$$

\section{Mate choice}

We tested female mate preferences for different claw colors using custom-built robotic crabs. Each robot consisted of a plaster claw replica (19.6-mm long, molded from a real male claw) attached to a metal arm that protruded above the test arena and controlled by a motor directly below the arena. The metal arm was programmed to perfectly imitate the claw waving pattern of this species. All robots waved synchronously at a rate of 6.7 waves $/ \mathrm{min}$. The only difference between the signals was the color of the claw.

We captured females wandering on the mudflat and tested their mate preferences on a level $60 \times 60 \mathrm{~cm}$ arena that was covered in a layer of mudflat sediment. The female was placed on one side of the arena in a small transparent cup that was remotely lifted once the trial started. A positive response was scored if the female moved directly toward, and stopped at the base of, one of the robotic crabs. If a female gave a startle response (i.e., ran to the edge of the arena as soon as they were released) or did not move for $3 \mathrm{~min}$ after release, they were retested three times and then excluded. Approximately $15 \%$ of females failed to respond in at least one trial. Females were able to observe the waving robots for two full wave cycles before being released.

Robotic crabs have been used successfully in A. mjoebergi mate choice trials in many previous studies (e.g., Reaney 2009; Kahn et al. 2014; Mowles et al. 2017a; Perez and Backwell 2017). As in choice trials in other species, the arena has a "no choice" area: the female is able to move in any direction and is not constrained to approach the waving robotic crabs. The choice area is extremely small relative to the no-choice area $(0.006 \%$ of the arena). A female approach to one of the robotic crabs does not indicate her final mate choice, but it does indicate her assessment of male quality. Under natural conditions, a mate-searching female is constantly surrounded by a cluster of waving males (2-8). As she searches, the males behind her leave the cluster and the males in front of her join in. The female then remains stationary for a period (presumably assessing the clustered males) and then quickly and directly approaches an individual male and enters his burrow. Her initial choice may depend on one or more of several male traits including wave rate (Callander et al. 2012; Vega-Trejo and Backwell 2017; Mowles et al. 2017a), wave timing (Kahn et al. 2014; Reaney et al. 2008), wave height (Perez and Backwell 2019), and claw length (Reaney 2009; Callander et al. 2012). Once inside the burrow, the female assesses multiple burrow characteristics and then either remains with the male or leaves the burrow to continue searching (Reaney and Backwell 2007). Mate choice is therefore a two-stage process: females first assess the male and then assess the male's burrow. Female behavior in mate choice trials using robotic crabs is similar to their natural behavior when approaching a male under natural conditions; the approach to the "male" once chosen is precise and does not involve any sudden change in direction toward the other "male" or any switching back and forth between options. Furthermore, in all cases where we have collected correlational data under natural conditions, and compared it with the results of choice trials, the results have been consistent (Callander et al. 2012).

\section{Experiment 1: two-choice trials with claw colors within and outside the natural range}

We placed two robotic crabs $5 \mathrm{~cm}$ apart and $20 \mathrm{~cm}$ away from (and directly facing) the female release point. We paired the five claw colors (white, light yellow, dark yellow, orange, and red) in all combinations, resulting in 10 two-choice tests. We changed the position of the claws between trials to control for possible side preferences. The number of trials for each color combination varied between 24 and 31 . 


\section{Experiment 2: three-choice trials}

We placed three robotic crabs $5 \mathrm{~cm}$ apart, $20 \mathrm{~cm}$ from the female release point and in an arc, so that they directly faced the female. We conducted four experiments using claws in different combinations: (i) white, dark yellow, red; (ii) dark yellow, orange, red; (iii) light yellow, dark yellow, orange; and (iv) white, light yellow, dark yellow. As for Experiment 1 , we changed the positions of the claws between trials. A total of 30 trials were conducted for each combination of colors.

\section{Experiment 3: two-choice trials with controlled varia- tion in hue, chroma, and intensity}

The painted claws used in Experiments 1 and 2 differed from each other in more than one parameter of color (hue, chroma, and intensity, see Fig. 2a). In this experiment we presented females with claws that had a similar value for two color parameters but differed with respect to the third. It is not possible to vary the parameters of color completely independently. We therefore maximized the change in a given parameter while holding the other two as constant as possible. In the first trial, the two claw models differed in hue but had similar chroma and intensity; in the second trial, the two options differed in chroma but had similar hue and intensity; in the third trial, they differed in intensity but had similar hue and chroma (see Fig 3). A total of 30 trials were conducted for each color combination. The trials were run as for Experiment 1.

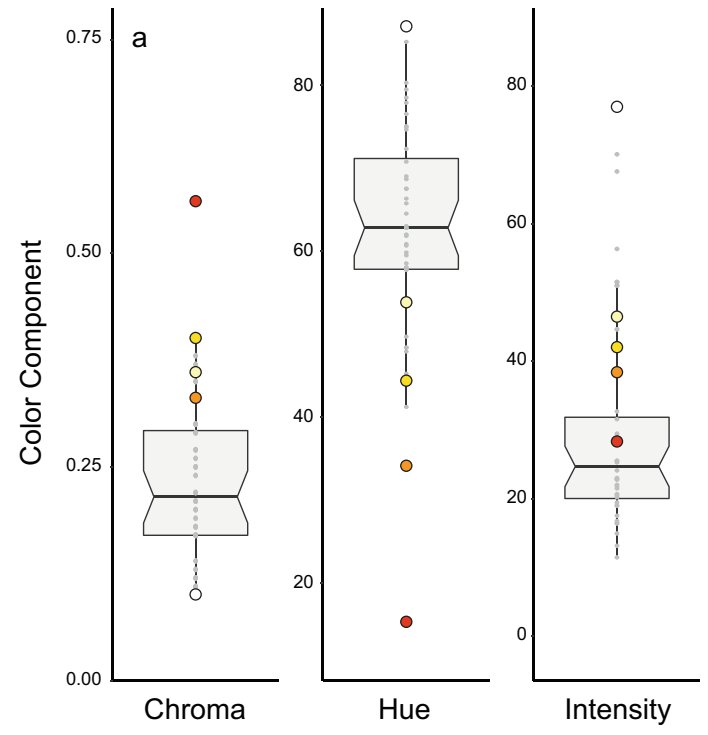

Fig. 2 (a) Box and whisker plots of chroma, hue, and intensity of natural claws $(N=40)$. Horizontal lines of the box represent the 25th percentile, median, and 75th percentile of each color component, and the whiskers represent the total range. The chroma, hue, and intensity of natural claws are shown as gray circles, and the values for the painted claws used in Experiments 1 and 2 are shown in their respective colors (white, light
In all experiments, the order of the trials was random. All females were tested only once to each color combination but some females in Experiments 1 and 2 were tested in more than one trial using different combinations of colors ( 94 females in 272 trials in Experiment 1; 69 females in 120 trials in Experiment 2). Females were only tested in one trial in Experiment 3 (90 females in 90 trials). Previous studies on A. mjoebergi have found no detectable effects on behavior from using females in more than one experimental choice trial (Milner et al. 2008; Reaney et al. 2008).

\section{Statistical analyses}

We tested for female preferences for particular colors (Experiments 1 and 2) using Bayesian multilevel models and included female identity as a random factor to account for the fact that some females were tested in more than one color combination. Specifically, for the two-choice tests (Experiment 1), we fitted a multilevel model with the female's color preference as the response variable $(0=$ whiter, $1=$ redder), color combination (10 in total) as a predictor variable, female identity as a random factor, and a Bernoulli response distribution (assuming equal probability for both possible outcomes). For the three-choice test (Experiment 2), we fitted a multilevel model with the female's color preference as the response variable $(0=$ whitest, $1=$ intermediate, $2=$ reddest $)$, color combination (4 in total) as a predictor variable, female identity as a random factor, and a categorical response distribution (assuming equal probability for each possible

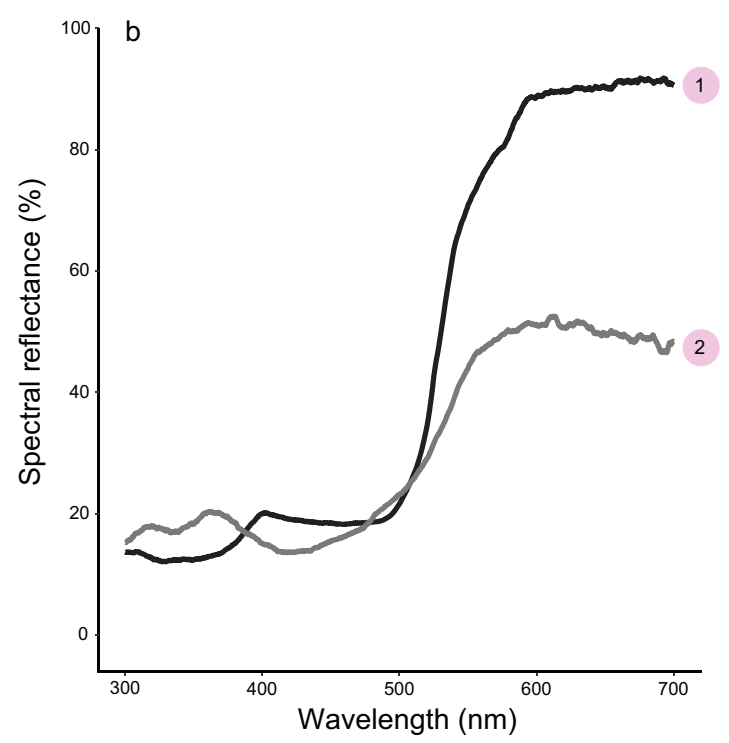

yellow, dark yellow, orange, and red). (b) Spectral reflectance of the claws of two males from the population: claws 1 and 2 differ in the height of the reflectance in the yellow region (intensity); the slope of the curve as the $\%$ reflectance rises (the chroma); and the point at which the curve starts rising (the hue) 

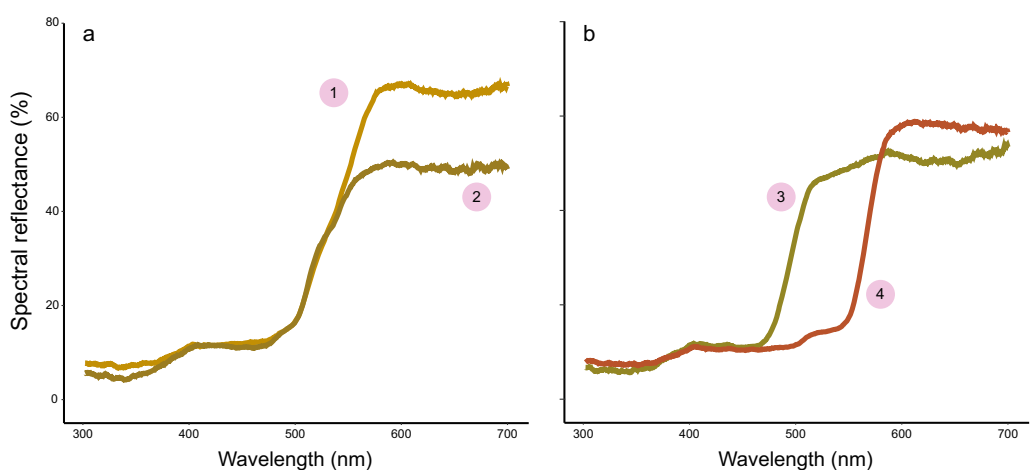
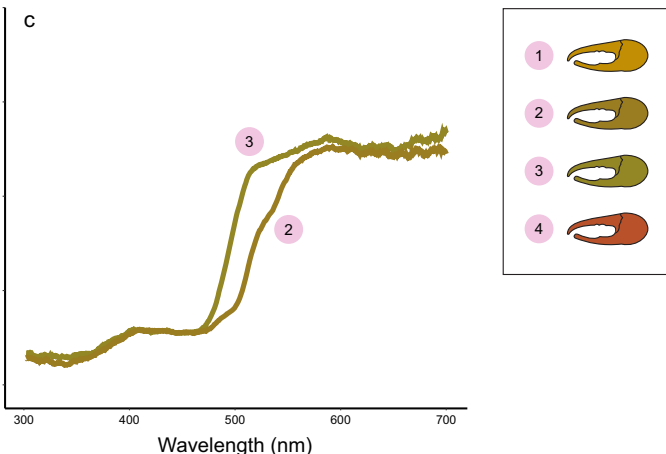

Fig. 3 Spectrographs of the painted claws used in the second set of twochoice trials. (a) Model claws differing in intensity. Paint 1 has higher intensity (i.e., is brighter) than paint 2; paint 1 has greater $\%$ spectral reflectance than 2 at, and above, peak wavelength (total reflectance between 400 and $700 \mathrm{~nm}=37 \%$ vs $30 \%$ ) but both have similar chroma (the slope of the line - from the wavelength at which spectral reflectance increases to the wavelength of peak reflectance- is the same; $C=0.41$ vs 0.40 ) and hue (the wavelength at which there is a dramatic increase in spectral reflectance is similar; $H=78$ vs 80 ). (b) Model claws differing in hue (the increase in spectral reflectance occurs at different wavelengths; $H$ $=84$ vs 54$)$ but with the similar chroma $(C=0.35$ vs 0.36$)$ and intensity (total reflectance $=28$ vs 33). (c) Model claws differing in chroma. Paint 3 has higher chroma/more saturated than paint $2(C=0.35 \mathrm{vs} 0.40)$ but both have similar hue ( $H=84$ vs 80 ) and intensity (total reflectance $=28$ vs 30 ) outcome). The Bayesian multilevel models were run using the brms package (Bürkner 2017) in R 2.10.1 (R core Team 2019). For each model, we ran four chains for 4000 iterations, with a warm-up period of 2000 iterations. Models were checked for convergence by inspecting R-hat values (R-hat $=1$ for both) and diagnostic plots. All parameter estimates are reported as means with $95 \%$ credible intervals. In Experiment 3, females were only used in one trial so the tested female preferences for claws differ in hue, chroma, or intensity using the exact binomial tests.

For Experiment 1, we also counted the total number of responses to each color over all ten color combinations and used a chi-squared test to determine if responses differed from that expected in the absence of color preferences.

\section{Results}

\section{Spectroscopy and color analysis}

Box and whisker plots of the intensity, chroma, and hue of 40 natural claws and the five painted claws used in Experiments 1 and 2 are shown in Fig. 2a. Light yellow, dark yellow, and orange painted claws fell within the species range for chroma, with red and white claws falling outside the range. With respect to hue, light yellow and dark yellow fell inside the range with orange falling just outside. Red and white claws were well outside the natural range. All claws with the exception of white were within the range of natural claws with respect to intensity. Figure $2 b$ shows the reflectance spectra for the claws of two males from the population and illustrates the extent to which natural claws of individual males differ from each other with respect to hue, chroma, and intensity.
The spectral reflectance of claws used in Experiment 3 is shown in Fig. 3. Although the colors of the claws, from a human perception of color, differed from the natural range of claw colors, the chroma, hue, and intensity of all four claws fell within the natural range of these parameters for the species.

\section{Experiment 1: two-choice trials with claw colors within and outside the natural range}

Results are shown in Fig 4. Females were more likely to choose light yellow claws over white claws (mean of posterior distribution [95\% credible interval] $=83.6 \%[68.4,94.4])$ and orange claws over white claws $(87.8 \%$ [71.5, 97.4]). Females were also less likely to choose red claws over orange claws $(27.2 \%[12.9,44.2])$ and dark yellow claws over light yellow claws $(31.9 \%[16.9,49.1])$. Females did not show any other color preferences.

When female responses in trials for each color combination were combined, the number of times each claw was selected by a female was white $=30$, light yellow $=79$, dark yellow $=$ 53 , orange $=71$, and red $=40$. The distribution of responses is significantly different from uniform, with white and red being under-represented $\left(\chi^{2}=30.86\right.$, d.f. $\left.=4 ; P<0.001\right)$. With white and red removed, we found no difference in the number of responses to light yellow, dark yellow, and orange $\left(\chi^{2}=\right.$ 5.24, d.f. $=2 ; P=0.09$ ).

Although white and red were selected against some trials, 30 females preferentially approached a white claw over the alternative, and 40 preferentially approached a red claw over the alternative. After removing the cases where white and red were pitted against each other, there were still 25 (32\%) cases in which females selected the red claw over the light yellow, dark yellow, or orange claw, and there were $17(21 \%)$ cases 
Fig. 4 Predicted probability that females chose the claw shown in the top row for each of the ten two-choice trials (Experiment 1). Solid points show the fitted values from the Bayesian multilevel model (mean of the posterior distribution and the $95 \%$ credible intervals). The dashed line indicates no preference (probability $=$ $50 \%$ ). Claw color combinations used in each trial are shown on the $\mathrm{x}$-axis. Trials in which females showed a high probability of response (preference) to the claws in the top row and those in which they showed a low probability of response to claws in the top row (i.e., a preference for the alternative) are indicated by an asterisk

Fig. 5 Predicted probability that females responded to each of the colored claws in the three-choice trials (Experiment 2). Solid points show the fitted values from the Bayesian multilevel model (mean of the posterior distribution and the $95 \%$ credible intervals). The dashed line indicates no preference (probability $=33 \%$ ). The asterisks indicate either a high (preference) or low probability of response to that claw color
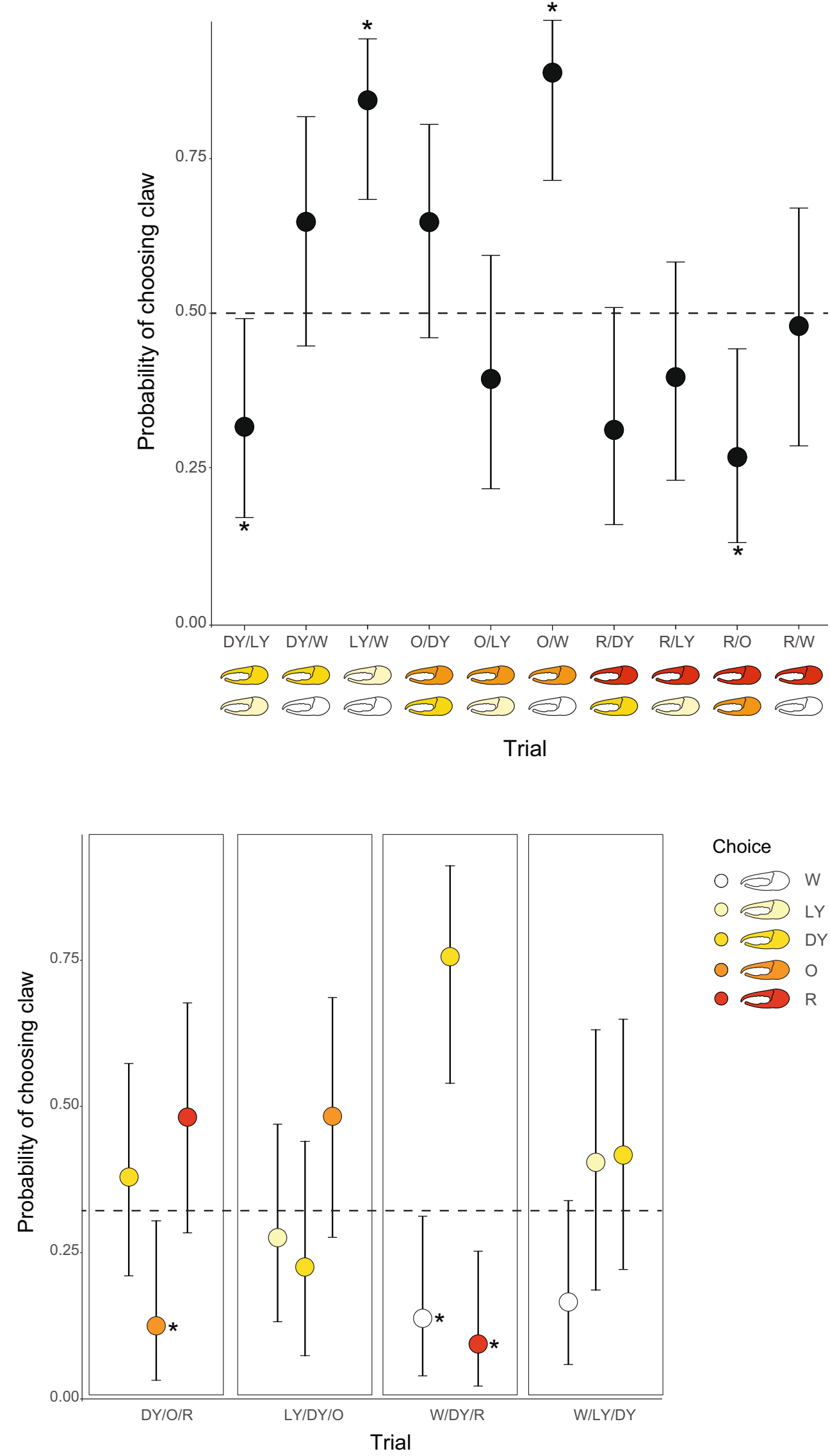

Choice

$0 \Longleftrightarrow w$

$0 \Longleftrightarrow$ LY

$0 \lesssim D Y$

$0 \curvearrowright 0$

$0 \curvearrowright R$ 
where the female preferentially approached the white claw over the light yellow, dark yellow, or orange claw.

\section{Experiment 2: three-choice trials}

The results of the three-choice trials are shown in Fig 5. Females were less likely to choose orange claws when tested with dark yellow and red claws $(13.6 \%[3.18,30.9])$. Females were also more likely to choose dark yellow claws (74.5\% $[54.1,90.8])$ and less likely to choose white claws $(14.9 \%$ $[4.05,31.3])$ or red claws $(10.7 \%$ [2.3, 25.4]) when white, dark yellow, and red claws were presented together.

\section{Experiment 3: two-choice trials with controlled varia- tion in hue, chroma, and intensity}

The results of Experiment 3 are given in Table 1. Females showed no significant preference for either option when claws differed in only in hue, chroma, or intensity.

\section{Discussion}

Although the use of color by animals is a rapidly growing research field, there are still relatively few empirical studies, especially in invertebrates, aimed at determining how color signals contribute to reproductive isolation. Although many color signals differ between species, identifying those features that are required by individuals to recognize, and respond to, a conspecific requires that only the signal of interest is manipulated, as was done in this study.

The results suggest that claw color is important in species recognition in A. mjoebergi. Although some females responded to red and white claws, they generally preferred light yellow and dark yellow claws when these were presented in combination with white or red claws and showed a significant preference for light yellow over white claws in twochoice tests. Females also prefer orange over both white and red claws even though orange claws fell outside the natural species range for hue. This, together with the fact that they did not discriminate between orange and light yellow claws or orange and dark yellow claws, suggests that the orange claws were recognized as being conspecific. In the three-choice

Table 1 Female preferences in trials with controlled variation in hue, chroma, and intensity $(n=30)$

\begin{tabular}{lll}
\hline & Choices & Binomial $P$ \\
\hline Paint 1 vs paint 2 (differ in intensity) & $20: 10$ & 0.10 \\
Paint 3 vs paint 4 (differ in hue) & $17: 13$ & 0.59 \\
Paint 3 vs paint 2 (differ in chroma) & $19: 11$ & 0.20 \\
\hline
\end{tabular}

tests, females showed a strong preference for dark yellow over white and red claws, suggesting some degree of stabilizing selection on claw color. Both these results suggest that claw color mediates species recognition in A. mjoebergi and support a previous study (Detto et al. 2006) that showed females are able to discriminate between conspecific claws and those of sympatric T. signata and that preference is based on color rather than pattern. They also support the finding that females use chromatic cues in mate choice (Detto 2007) and suggest that females can distinguish between red and shorter wavelength hues.

Overall, the results of Experiments 1 and 2 showed little evidence that females show consistent preferences based on intraspecific differences in claw color. One possible explanation is that the painted claws did not represent the full range of parameters characteristic of natural claws. Females may have a threshold preference in which color parameters above particular value are all considered equally "attractive." However, the fact that females discriminated between different shades of yellow (Experiment 1) and between orange and dark yellow claws (Experiment 2) would argue against this.

The results of Experiment 3 provided little evidence that the lack of consistent preferences seen in Experiments 1 and 2 was due to the interaction between single parameters of color (hue, chroma, or intensity). Neither chroma or hue independently affected female choice suggesting that any preferences displayed by females based on color were facilitated by the simultaneous evaluation of multiple color components. However, it is worth noting that twice as many females preferred the more intense (brighter) claw over the duller alternative when differences in chroma and hue were minimized. This result, together with the fact that females showed a significant preference for light yellow over dark yellow claws in two-choice tests, suggests that claw brightness may have some influence mate choice in this species and suggests an avenue for future research into the effects of signaling background on signal perception and preference. A previous study on this species showed that females did not discriminate between two identically colored yellow claws presented in the shade and in full sunlight (Milner et al. 2008). However, it is possible that the detectability of claws that differ in brightness varies according to the signaling environment.

Many of the striking yellow, orange, and red colors seen in animals including crustaceans (Wade et al. 2005, Maoka 2011) are due to carotenoids. In the blue crab, male preferences for females with red claws over claws colored with various shades of orange have led to speculation that coloration is indicative of quality (Baldwin and Johnsen 2012). Associations between the intensity of carotenoid-based ornamentation and various measures of individual quality have been found in many taxa (e.g., Helfenstein et al. 2010; Mehlis et al. 2013; Garratt and Brooks 2012; Nathan et al. 2018) and female preferences for brighter, more intensely 
colored signals appear widespread, being reported in several fish (e.g., Kodric-Brown 1993; Milinski and Bakker 1990) and bird species (reviewed in Hill 1999). It is possible that the range of claw colors (from light yellow to orange) found in natural populations of $A$. mjoebergi males reflects different concentrations and/or composition of ingested or bioconverted carotenoids. However, the results of our experiments provide little evidence to suggest that female mating decisions are based on differences in claw color that may reflect differences in male quality. Females were less likely to approach dark yellow claws than light yellow claws in twochoice tests and showed no preference for orange claws except in combination with white and red claws. The claws used in this study lacked UV and it is possible that females require UV reflectance to discriminate subtle differences in hue. Further tests using claws that differ in color but reflect $\mathrm{UV}$ are required to test this possibility.

Few studies have investigated if intraspecific variation in color signals is related to other aspects of behavior such as courtship intensity (Svensson and Wong 2011). Such a relationship could explain the lack of consistent female preferences in this study if wave rate varies with claw color. In our experiments, wave rate did not differ between stimuli but it has been shown to influence female mating decisions in A. mjoebergi. Females show strong preferences for faster wave rates under natural conditions (Callander et al. 2012) and in tests using robotic crabs (Vega-Trejo and Backwell 2017). Astruca mjoebergi males with more vigorous displays have been found to have higher performance capacities (Mowles et al. 2017b). We do not know if claw color is a costly and hence honest signal of male quality (see Olson and Owens 1998) or if there is any relationship between color and courtship intensity. However, since wave rate appears to be an accurate display of quality (Mowles et al. 2017b), it is possible that some combination of wave rate and color could be used by females in mate choice decisions. In this sense, claw color may represent only one component of a multi-component signal that is used by females to assess male quality.

It is also possible that females do not attend to variation in conspecific claw color in mate choice decisions, but color is important in competitive interactions between males. In birds (Mateos and Carranza 1997; Pryke et al. 2002; Pryke and Griffith 2006) and lizards (Hamilton et al. 2013), color (due to carotenoid-based pigments) has been shown to influence the outcome of male-male agonistic interactions. For example, in frill-necked lizards, males processing more colorful redorange frill patches have higher competitive ability and greater contest success than males with less colorful displays (Hamilton et al. 2013). Although it is not known if claw color affects the outcomes of contests in A. mjoebergi, a previous study showed that the presence or absence of UV had little effect on the tendency of males to initiate fights with competitors (Detto and Backwell 2009). If claw color is carotenoid derived in these crabs as is the case in many crustaceans, competition over food sources from which pigments are derived could be related to competitive ability.

Finally, if crabs do not distinguish between subtle differences in claw color as suggested in this study, claws may differ in color for reasons other than signaling to conspecifics. For example, pigmentation may be related to the size or strength of the claw that in turn affects the outcome of fights (Perez et al. 2015). In the stone crab (Menippe mercenaria), for example, black claws are stronger than yellow claws (Caro 2018). Alternatively, color may affect the claws' thermoregulatory function as a heat sink (Darnell and Munguia 2011).

The evolution of conspicuous coloration has been the focus of many studies, particularly in birds. Many of these studies demonstrate how indicator models of sexual selection, and in particular female choice, have driven the evolution of colorful plumage in males because of the relationship between color and individual color components (intensity, hue, and chroma) and measures of individual male quality (e.g., Class et al. 2019; Bruinjé et al. 2019; Lui et al. 2018). Little emphasis has been placed on studies that show a lack of female preferences based on intraspecific color signals, despite their condition dependence. For example, in the colorful jumping spider Habronattus pyrrithrix, females do not attend to the red facial coloration of males which is condition dependent (Taylor et al. 2014). Although we do not know if claw color is condition dependent in fiddler crabs, our study adds to the limited number of studies that argue against intraspecific female choice being a major factor influencing the evolution of colorful male displays. Instead, it suggests that color is important in species recognition and as such should not necessarily evolve to be costly, condition dependent, or elaborate but rather be under stabilizing selection to be unambiguous.

Acknowledgments We would like to thank Jia Huei Chen for helping with the fieldwork and Luke Holman for his help with statistical analyses.

Funding The work was supported by an Australian Research Council Discovery Grant to PRYB (DP160100316) and an Open University Travel and Subsistence grant to MLD (RTSF-17-11).

Data availability All data sets generated during and/or analyzed during the current study are available from the corresponding author on reasonable request.

\section{Compliance with ethical standards}

Conflict of interest The authors have no conflict of interests.

Ethical approval This research was approved by the Australian National University Animal Ethics Committee (permit A2015/54). We limited the handling and the amount of time each crab was used as much as possible. No crab was injured during the research, and they all continued their regular activities after release. Between trials, the females were kept in the shade, in individual cups with a small amount of seawater. Females were used in a maximum of five different trials and then released to continue mate-searching. Under natural conditions, females visit up to 
20 males before selecting a mate, and repeated testing did not appear to stress females or alter their behavior in any way. The work was conducted under a research permit from the Darwin City Council (permit no. 3648724).

Open Access This article is licensed under a Creative Commons Attribution 4.0 International License, which permits use, sharing, adaptation, distribution and reproduction in any medium or format, as long as you give appropriate credit to the original author(s) and the source, provide a link to the Creative Commons licence, and indicate if changes were made. The images or other third party material in this article are included in the article's Creative Commons licence, unless indicated otherwise in a credit line to the material. If material is not included in the article's Creative Commons licence and your intended use is not permitted by statutory regulation or exceeds the permitted use, you will need to obtain permission directly from the copyright holder. To view a copy of this licence, visit http://creativecommons.org/licenses/by/4.0/.

\section{References}

Baldwin J, Johnsen S (2012) The male blue crab, Callinectes sapidus, used both chromatic and achromatic cues during mate choice. J Exp Biol 215:1184-1191

Baldwin J, Johnson S (2009) The importance of color in mate choice of the blue crab Callinectes sapidus. J Exp Biol 212:3762-3768

Bruinjé AC, Coelho FEA, Paiva TMA, Costa GC (2019) Aggression, color signaling, and performance of the male color morphs of a Brazilian lizard (Tropidurus semitaeniatus). Behav Ecol Sociobiol 73(6): 72

Bürkner P (2017) An R package for Bayesian multilevel models using Stan. J Stat Softw 80:1-28

Callander S, Jennions MD, Backwell PRY (2012) The effect of claw size and wave rate on female choice in a fiddler crab. J Ethol 30:151-155

Caro T (2018) The functional significance of coloration in crabs. Biol J Linn Soc 124:1-10

Class B, Kluen E, Brommer JE (2019) Tail colour signals performance in blue tit nestlings. J Evol Biol 32:913-920

Cuadrado M (2000) Body colors indicate reproductive status of female common chameleons: experimental evidence for intersex communication function. Ethology 106:79-91

Darnell MZ, Munguia P (2011) Thermoregulation as an alternative function of the sexually dimorphic fiddler crab claw. Am Nat 178:419428

Detto T (2007) The fiddler crab Uca mjoebergi uses colour vision in mate choice. Proc R Soc B 274:2785-2790

Detto T, Backwell P (2009) The fiddler crab Uca mjoebergi uses ultraviolet cues in mate choice but not aggressive interactions. Anim Behav 78:407-411

Detto T, Backwell PRY, Hemmi JM, Zeil J (2006) Visually mediated species and neighbour recognition in fiddler crabs (Uca mjoebergi and Uca capricornis). Proc R Soc B 273:1661-1666

Detto T, Jennions MJ, Backwell PRY (2010) When and why do territorial coalitions occur? Experimental evidence from a fiddler crab. Am Nat 175:E119-E125

Endler JA (1990) On the measurement and classification of colour in studies of animal colour patterns. Biol J Linn Soc 41:315-352

Ferns PN, Hinsley SA (2008) Carotenoid plumage hue and chroma signal different aspects of individual and habitat quality in tits. Ibis 150 : $152-159$

Ferreira M, Ferguson JWH (2002) Geographic variation in the calling song of the field cricket Gryllus bimaculatus (Orthoptera: Gryllidae) and its relevance to mate recognition and mate choice. J Zool (Lond) 257:163170
Garratt M, Brooks RC (2012) Oxidative stress and condition-dependent sexual signals: more than just seeing red. Proc Biol Sci 279:31213130

Hamilton DG, Whiting MJ, Pryke SR (2013) Fiery frills: carotenoidbased coloration predicts contest success in frill neck lizards. Behav Ecol 24:1138-1149

Helfenstein F, Losdat S, Moller AP, Blount JD, Richner H (2010) Sperm of colourful males are better protected against oxidative stress. Ecol Lett 13:213-222

Hill GE (1999). Mate choice, mate quality and carotenoid-based plumage coloration. In: Adams N, Slotow R (eds) Proc. 22 Int Ornithol Congr Durban. Bird Life South Africa pp 1654-1668.

Horch K, Salmon M, Forward R (2002) Evidence for a two pigment visual system in the fiddler crab, Uca thayeri. J Comp Physiol A 188:493-499

Hyatt G (1974) Physiological and behavioural evidence for colour discrimination by fiddler crabs (Brachyura, Ocypodidae, Genus $U c a$ ). In: Vernberg V (ed) Physiological ecology of estuarine organisms. University of South Carolina Press, Columbia, pp 333-365

Jiggins CD, Naisbit RE, Coe RL, Mallet J (2001) Reproductive isolation caused by colour pattern mimicry. Nature 411:302-305

Jordão JM, Cronin TW, Oliveira RF (2007) Spectral sensitivity of four species of fiddler crabs (Uca pugnax, Uca pugilator, Uca vomeris and Uca tangeri) measured by in situ microspectrophotometry. J Exp Biol 210:447-453

Kahn AT, Holman L, Backwell PRY (2014) Female preferences for timing in a fiddler crab with a synchronous courtship waving display. Anim Behav 98:35-39

Klomp DA, Stuart-Fox D, Cassidy EJ, Norhayati A, Ord TJ (2017) Color pattern facilitates species recognition but not signal detection: a field test using robots. Behav Ecol 28:597-606

Kodric-Brown A (1993) Female choice of multiple male criteria in guppies: interacting effects of dominance, coloration and courtship. Behav Ecol Sociobiol 32:415-420

Losos JB (1985) An experimental demonstration of the speciesrecognition role of Anolis dewlap color. Copeia 1985:905-910

Lui Y, Scordato HSC, Safran R, Evans M (2018) Ventral colour, not tail streamer length, is associated with seasonal performance in a Chinese population of barn swallows (Hirundo rustica gutturalis). J Ornithol 159:675-685

Maoka T (2011) Carotenoids in marine animals. Mar Drugs 9:278-293

Mateos C, Carranza J (1997) The role of bright plumage in male-male interactions in the ring-necked pheasant. Anim Behav 54:12051214

Mehlis M, Hilke LK, Bakker TCM (2013) Attractive males have faster sperm in three-spined sticklebacks Gasterosteus aculeatus. Curr Zool 59:761-768

Milinski M, Bakker TCM (1990) Female sticklebacks use male coloration in mate choice and hence avoid parasitized males. Nature. 344: 330-333

Milner RNC, Jennions MD, Backwell PRY (2008) Does environmental context of a signaling male influence his attractiveness? Anim Behav 76:1565-1570

Mowles SL, Jennions M, Backwell PRY (2017a) Robotic crabs reveal that female fiddler crabs are sensitive to changes in male display rate. Biol Lett 14:20170695

Mowles SL, Jennions M, Backwell PRY (2017b) Multimodal communication in courting fiddler crabs reveals male performance capacities. $R$ Soc Open Sci 4:161093

Nathan PM, Torres R, Welch AJ, Adama J, Bonillas-Monge ME, Felis J, Lopez-Marquez L, Martinez-Flores A, Wiley AE (2018) Carotenoid-based skin ornaments reflect foraging propensity in a seabird, Sula leucogaster. Biol Lett 14:20180398

Olson VA, Owens IPF (1998) Costly sexual signals: carotenoids rare, risky or required? Trends Ecol Evol 13:510-514 
Pauers MJ, Ehlinger TJ, Mckinnon JS (2010) Female and male visually based mate preferences are consistent with reproductive isolation between populations of Lake Malawi endemic Labeotropheus fuelleborni. Curr Zool 56:65-72

Perez DM, Backwell PRY (2017) Female preferences for conspecific and heterospecific wave patterns in a fiddler crab. J Exp Mar Biol Ecol 486:155-159

Perez DM, Backwell PRY (2019) Selection for conspicuous visual signals in a fiddler crab. Behav Ecol Sociobiol 73:61

Perez DM, Rosenberg MS, Pie MR (2012) The evolution of waving displays in fiddler crabs (Uca spp., Crustacea: Ocypodidae). Biol J Linn Soc 106:307-315

Perez DM, Heatwole SJ, Morrell LJ, Backwell PRY (2015) Handedness in fiddler crab fights. Anim Behav 110:99-104

Pryke SR, Griffith SC (2006) Red dominates black: agonistic signaling among head morphs in color polymorphic Gouldian finch. Proc R Soc Lond B Biol Sci 273:949-957

Pryke SR, Andersson S, Lawes MJ, Piper SE (2002) Carotenoid status signaling in captive and wild red-collared widowbirds: independent effects of badge size and color. Behav Ecol 13:622-631

R Core Team (2019) R: A language and environment for statistical computing. R Foundation for Statistical Computing, Vienna https:// www.R-project.org

Rajkumar P, Rollman SM, Cook TA, Layne JE (2010) Molecular evidence for colour discrimination in the Atlantic sand fiddler crab, Uca pugilator. J Exp Biol 213:4240-4248

Reaney LT (2009) Female preference for male phenotypic traits in a fiddler crab: do females use absolute or comparative evaluation? Anim Behav 17:139-143

Reaney LT, Backwell PRY (2007) Temporal constraints and female preference for burrow width in the fiddler crab, Uca mjoebergi. Behav Ecol Sociobiol 61:1515-1521

Reaney LT, Simms RA, Simms SWM, Jennions MD, Backwell PRY (2008) Experiments with robots explain synchronized courtship in fiddler crabs. Curr Biol 18:R62-R63

Saetre G-P, Moum T, Stanislav B, Miroslav K, Adamjan M, Moreno J (1997) A sexually selected character displacement in flycatchers reinforces premating isolation. Nature 387:589-592
Seehausen O, van Alphen JJM (1998) The effect of male coloration on female mate choice in closely related Lake Victoria cichlids (Haplochromis nyererei complex). Behav Ecol Sociobiol 42:1-8

Silbiger N, Munguia P (2008) Carapace colour change in Uca pugilator as a response to temperature. J Exp Mar Biol Ecol 355:41-46

Smith SD (2014) Quantifying color variation: improved formulas for calculating hue with segment classification. Appl Plant Sci 2: 1300088

Svensson PA, Wong BBM (2011) Carotenoid-based signals in behavioural ecology: a review. Behaviour 148:131-189

Takashita F (2019) Color changes of fiddler crab between seasons and under stressful conditions: patterns of changes in lightness differ between carapace and claw. J Exp Mar Biol Ecol 511:113-119

Taylor LA, Clark DL, McGraw KJ (2014) Natural variation in conditiondependent display colour does not predict male courtship success in a jumping spider. Anim Behav 93:267-278

Vega-Trejo R, Backwell PRY (2017) Testing female preferences under more natural conditions: a case study. Behav Ecol Sociobiol 71:81

Wade N, Goulter KC, Wilson KJ, Hall MR, Degnan BM (2005) Esterified astaxanthin levels in lobster epithelia correlate with shell colour intensity: potential role in crustacean shell colour formation. Comp Biochem Physiol B 141:307-313

Wiernasz DC, Kingsolver JG (1992) Wing melanin pattern mediates species recognition in Pieris occidentalis. Anim Behav 43:89-94

Williams TH, Mendelson TC (2011) Female preference for male colouration may explain behavioural isolation in sympatric darters. Anim Behav 82:683-689

Wolfrath B (1993) Observations on the behaviour of the European fiddler crab Uca tangeri. Mar Ecol Prog Ser 111-118.

Zeil J, Hemmi JM, Backwell PRY (2006) Fiddler crabs. Curr Biol 16: R40-R41

Publisher's note Springer Nature remains neutral with regard to jurisdictional claims in published maps and institutional affiliations. 